\title{
Minas de carvão: trabalho também de mulheres
}

Dos subterrâneos da história: as trabalhadoras das minas de carvão de Santa Catarina (1937-1964).

CAROLA, Carlos Renato.

Florianópolis: Ed. da UFSC, 2002. 262 p.

Dos subterrâneos da história, do historiador Carlos Renato Carola, revisita a região carbonífera de Santa Catarina, dando ênfase às histórias peculiares de mulheres e homens que fizeram e fazem parte da indústria do carvão no sul catarinense. Carola se insere na esteira dos trabalhos voltados à região, a qual já vem sendo pesquisada pelas ciências sociais e humanas há cerca de 20 anos. Porém, apesar de percorrer um espaço geográfico já conhecido dos cientistas sociais, o historiador busca interpretar diferentemente esse espaço, através de uma abordagem histórica que se utiliza magistralmente da categoria de gênero. Se do ponto de vista temático o 'mundo do carvão' não constitui matéria inédita, é o modelo teórico-metodológico de Carola que ganha mérito nessa obra, ao mesmo tempo prazerosa, mas que apresenta densidade analíica, fruto de uma pesquisa de 
mestrado em História desenvolvida na Universidade Federal de Santa Catarina, a qual não negou, em nenhum instante, a importância de pesquisas anteriores sobre o tema.

Nesse sentido, ao ler-se Dos subterrâneos da história, é importante lembrar-se de pesquisas como a da socióloga Terezinha G. Volpato, tais como A pirita humana, ${ }^{1}$ de 1984 . Destinada a descrever as condições de vida e as relações sociais que envolviam a classe trabalhadora mineira na região de Criciúma, Volpato havia dado visibilidade aos mineiros catarinenses, auxiliando também no processo de legitimidade e reconhecimento político e acadêmico da luta dessa classe no cenário regional. Entretanto, sua narrativa, mesmo que excitante, reduzia o caráter do conceito de classe trabalhadora mineira, na medida em que posicionava essa mesma classe como uma entidade que "nada possui, apenas sua força de trabalho". Isso fez com que sua obra não privilegiasse a interlocução da experiência no processo de formação dos 'mineiros catarinenses'. Assim, o cenário desenhado por Volpato havia sido constituído pela marca da redução do trabalhador mineiro à condição de uma pirita - termo que designa o resíduo da indústria carbonífera. Dessa forma, o trabalhador fora retratado como um ser compelido à degradação e à escuridão do trabalho árduo da mina. Volpato não privilegiou a categoria da experiência e, muito menos, a de gênero, que para Carola são fundamentais para se entender a vida nas carboníferas.

Partindo em outra direção, o cenário obscuro, degradante e sofrível das minas é uma espécie de 'rio de Heráclito' a ser transposto em Dos subterrâneos da história. Nessa obra, o historiador opta por investigar as minas de carvão adicionando à perspectiva de classe as categorias do gênero e da experiência. Com isso, a história do 'mundo do carvão catarinense' passa a ter espaço para os diferentes sujeitos que o constituem, especialmente as mulheres.

Carola fala de mineiros, mas principalmente das trabalhadoras das minas. Ele traça histórias que se constroem desde o café da manhã nas casas operárias e que se estendem depois da jornada de trabalho. São histórias que acontecem nos mundos íntimo e público; histórias que são experienciadas no banho, no lazer, no sexo, mas também no futebol, na missa e nos bailes.

Para o autor, é impossível pensar a mina de carvão sem a presença marcante dos mundos íntimos e públicos que a serpenteiam e que por muito tempo não se fizeram perceber nas inúmeras fontes. Até parece que a indústria do carvão "surgiu, cresceu e desapareceu sem a participação dos trabalhadores" (p. 23). Essa premissa do historiador o conduz à constatação de que uma outra faceta da história social do mundo do carvão catarinense também esteve durante muito tempo 'não dita' e que dizia respeito diretamente à (in)visibilidade das trabalhadoras das minas.

É nesse sentido que o autor busca historicizar a presença das mulheres em um mundo de trabalho pretensamente masculino,

não somente porque [as mulheres] trabalharam nas minas, mas também porque foram elas que assumiram, exclusivamente, os trabalhos da casa, o cuidado das crianças e a comida na mesa. Sem o trabalho doméstico, o homem não suportaria trabalhar no 'subterrâneo das trevas' e a indústria carbonífera não teria se viabilizado economicamente (p. 23).

Quem são essas mulheres? Inicialmente, Carola percorre as trajetórias das escolhedeiras, as mulheres que classificavam o carvão vindo do subsolo. As escolhedeiras são os sujeitos de uma história de divisão de papéis atribuídos a homens e mulheres; são as extensões, os ligamentos e também as fugas que perpassam os temas do trabalho na mina e da manutenção da casa, da família, da economia doméstica, temas percorridos pelo autor. E é a categoria de gênero, explicitada desde o início pelo autor como sendo "a construção social da divisão entre os sexos", que possibilita tanto a leitores como leitoras perceber a complexidade das tramas historicamente constituídas no ambiente carbonífero onde mulheres e homens construíram e foram alvo de métodos de controle social, mas também se utilizaram de operações estratégicas, táticas ou improvisações para as suas realizações pessoais.

O livro é dividido em quatro capítulos e chama a atenção pela clareza e objetividade, as quais fazem com que a leitura seja fluida. Além da fluidez, pesquisadores e pesquisadoras de vários campos do conhecimento, desde a economia até a psicologia, podem encontrar na obra um importante modelo de pesquisa em gênero e história, na medida em que o autor transita facilmente entre aquela categoria de análise e as fontes já conhecidas da história do mundo carbonífero catarinense. Mas Carola vai além e apresenta-nos uma série de outras fontes, tais como entrevistas e uma boa dose de erudição que vai da literatura consagrada sobre os trabalhadores do século XIX na Europa até a economia. 
No primeiro capítulo, podemos nos preparar para uma descrição minuciosa do trabalho das mulheres nas minas, suas práticas de controle e de resistência às políticas das empresas e à visão convencional [masculina] de produção. Se as mulheres são invisíveis na extração do carvão no subsolo, isso não significa que elas não participavam no processo de beneficiamento desse produto. Logo, a idéia predominante no senso comum de que não havia mulheres trabalhando nas minas de carvão começa a ser categoricamente contestada pelo autor, na medida em que Carola dá voz às escolhedeiras - as trabalhadoras que classificavam o carvão vindo das minas.

Descrever esse trabalho significa também demonstrar como ocorria o transporte e o pagamento pelo serviço realizado pelas escolhedeiras. No processo de emprego das mulheres nas minas, o autor constata que, ao longo das trajetórias individuais às quais teve acesso, houve uma ânsia constante e contínua pelo aumento da produtividade das trabalhadoras. Já que as trabalhadoras estavam inseridas no processo produtivo do carvão e legitimadas na função de escolhedeiras, pensar o seu cotidiano por meio do gênero passou a significar para 0 autor que 0 dia-a-dia das mulheres nas minas "configurava-se também por divisões, competições e, conseqüentemente, conflitos e intrigas" (p. 23), não somente entre patrões e empregadas, homens e mulheres, como também entre empregadas e empregadas, mulheres e mulheres.

A partir desse capítulo, qualquer leitor ou leitora percebe que a história do mundo do carvão catarinense não pode ser mais interpretada somente pela ótica empresarial (o fortalecimento das empresas e das elites do ramo no sul do estado), política (as lutas dos sindicatos dos mineiros pelos seus direitos como classe trabalhadora homogênea) ou econômica (benefícios ou malefícios advindos da exploração do carvão na região). Trata-se de histórias mais complexas, particulares, experimentadas em escalas 'microscópicas' localizadas dentro da indústria.

No segundo capítulo, Carola se dirige à vila operária, esse local de atração de migrantes, espaço de atuação das companhias carboníferas onde "praticamente tudo pertencia aos donos das minas: os terrenos, as casas, os clubes de festas e dança, os clubes de futebol, o armazém e a escola" (p. 97). É o capítulo que corresponde à visibilidade histórica dos fluxos que percorrem os caminhos que levam mulheres e homens às minas pela manhã, que os trazem de volta no final da jornada. Mas a vila operária também engendra práticas culturais como a das 'fofocas' entre mães que ficam cuidando de seus filhos em casa. Ela também articula práticas econômicas como o gerenciamento da despensa da família, cria vizinhanças, afetos e desafetos, faz transitar e mostrar corpos de homens e de mulheres, expõe e controla condutas, incide sobre a moral. O autor dá espaço para o trato com temas como mudança de hábitos, a transição de modos de vida que se fazem visíveis através das redes de solidariedade praticadas entre os/as trabalhadores/ as nas vilas. Para Carola, as vilas operárias são os espaços das mulheres, áreas de sua 'outra' jornada de trabalho, onde "buscar água e lenha e cuidar do orçamento familiar, além dos afazeres tradicionais da casa, eram tarefas predominantemente femininas" (p. 118).

Já no terceiro capítulo o autor historiciza o tempo do não-trabalho, o tempo no qual homens e mulheres 'cuidavam de si'; quando suas imagens eram construídas através da experiência da participação nas festas, na missa, no jogo de futebol; quando o banho tornava-se espaço de prazer, de descanso, de higiene e de sexo. Aqui o historiador pede licença para adentrar a vida íntima da casa operária e, sobre o banho dos homens, por exemplo, Carola dá plena voz à experiência das mulheres. Certamente o terceiro capítulo traz à tona a força plena das relações entre gênero e história que são a base do trabalho de pesquisa. Citando uma trabalhadora das minas, Iracema Stefani, o autor enfatiza a constituição histórica dos papéis masculinos e femininos dentro da casa de mineiros e mineiras:

[...] a gente - dizia ela - é que tinha que lavar as costas dele, do marido, porque não existia banheiro nem chuveiro, não existia água encanada. [...] Então tomava banho de banheira; enchia a banheira d'água, ele lavava o rosto, a frente, ficava de calção, de cueca, e a gente lavava as costas (p. 148).

Contraposta à feminização das atividades em nível privado, a masculinização pública do trabalho das minas de carvão é tratada no quarto capítulo. Esse trabalho passa a ocorrer com maior força a partir do segundo pós-guerra, por meio da difusão da modernização da atividade extrativista e também da mecanização de vários setores da indústria. O capítulo quarto é importante também sob o ponto de vista teórico, na medida em que é o espaço da discussão em torno do gênero e da experiência como categorias de análise. 
A partir da modernização, o autor nos lembra que foram reforçados os estereótipos da mulher frágil, da sua 'naturalidade' para as 'tarefas domésticas' e para o 'trabalho leve'. Carola mostra que pressões econômicas e preconceitos sociais denegaram as mulheres do espaço de trabalho da mina a partir daquele momento como um elemento legítimo da comunidade mineradora e reforçaram os papéis tradicionais de boa mãe, boa esposa e boa dona de casa. Divisões como 'trabalho pesado' e 'trabalho leve' fizeram com que fosse construída a história das minas como a história dos operários mineiros. Além disso, a marca do 'trabalho leve' para as mulheres apresentava a carga pejorativa da qualidade de seu trabalho (leve, portanto frágil e, do ponto de vista pragmático, insignificante).

Dos subterrâneos da história se desenha como uma obra de referência dentro da história social de Santa Catarina, apresentando, obviamente, alguns limites. Ao dar visibilidade à experiência de mulheres em quase todas as atividades que tangenciam ou que atingem $o$ centro da indústria carbonífera, enfatizando a importância das mulheres no 'mundo do carvão' com relação à divisão do trabalho e à atribuição dos papéis sexuais, parece que o autor, em certos momentos, posiciona as escolhedeiras em um espaço de 'despolitização' oficial. Fica a sugestão de que os sindicatos e as entidades assistenciais somente trabalharam no sentido de transformar as escolhedeiras em boas donas de casa ou boas mães. Nesse sentido, toda a resistência e as táticas mostradas pelas mulheres durante o tempo em que trabalharam majoritariamente nas minas como escolhedeiras ou como fiscais de produção parecem ter se desmanchado no ar com o processo de masculinização do segundo pósguerra. Não obstante, a presença e a atuação das mulheres dentro dessas instituições correspondem a um espaço amplo de pesquisa na região carbonífera sob o enfoque de gênero.

Ao final dessa leitura, torna-se difícil pensar as minas de carvão de Criciúma - e, por conseguinte, de outras regiões do Brasil - como um todo orgânico e homogêneo e masculino. Ao buscar histórias vivas, que dão espaço a intersubjetividades, em um exemplo da possibilidade de revisitação histórica de temas consagrados das ciências sociais e humanas em Santa Catarina, Carola não se furtou ao desafio de interpretar com um novo olhar as minas de carvão de Criciúma. Afinal, pensar as minas significa pensar seus trabalhadores mais visíveis, os mineiros, mas também implica conhecer e percorrer as condições materiais e culturais que possibilitam esse trabalho, seu café da manhã, seu banho. Implica também considerar sua porção feminina, já que se trata de uma região que economicamente dependera quase que exclusivamente do carvão para o desenvolvimento econômico, o que fazia com que houvesse a necessidade de se empregar muita mão-de-obra, tanto masculina quanto feminina. Porque minas de carvão, pretensamente trabalho de homens, também foi trabalho de mulheres.

' VOLPATO, Terezinha Gascho. A pirita humana: os mineiros de Criciúma. Florianópolis: Ed. da UFSC/ALESC, 1984.

Jó Klanovicz Universidade Federal de Santa Catarina 